\title{
The immediate post-operative period following intestinal and multi-visceral transplant is marked by profound fluxes of sodium and fluid: the Cambridge experience
}

\author{
A. Wiles, A. Butler, H. Tincknell, S. Duncan, B. Chukualim, M. Manaligod, P. Gibbs, N. V. Jamieson, \\ R. K. Praseedom, C. J. Watson, J. M. Woodward and S. J. Middleton \\ Addenbrooke's, Cambridge University Teaching Hospital, CB20QQ, UK
}

As the outcome of small intestinal and multi-visceral transplants improves, more intestinal failure patients are having the procedure as an alternative to problematic parenteral nutrition. The post-operative challenges faced by this group of patients due to infection and rejection are well documented. We have observed large fluid shifts and sodium $(\mathrm{Na})$ loss complicating post-operative care in these patients.

Since 2007, we have carried out 13 transplants in 12 patients. During the first post-operative month, fluid and Na balance are strictly monitored. The volume and electrolyte content of urine, stomal, naso-gastric and all drain output are measured as well as urine osmolarity. We have witnessed some of our patients losing up to molar quantities of urinary $\mathrm{Na}$ in a day. These fluxes do not seem to be driven by excessive fluid infusion, as CVP and body weight remain largely unchanged.

\begin{tabular}{|c|c|c|c|c|c|c|c|c|c|c|c|c|}
\hline \multirow[b]{2}{*}{ Day } & \multicolumn{2}{|c|}{ Total $\mathrm{Na}(\mathrm{mmol})$} & \multicolumn{2}{|c|}{ Total vol 1} & \multicolumn{2}{|c|}{ Urine $\mathrm{Na}$} & \multicolumn{2}{|c|}{ Urine vol } & \multicolumn{2}{|c|}{ Stoma $\mathrm{Na}$} & \multicolumn{2}{|c|}{ Stoma vol } \\
\hline & Mean & $\mathrm{SD}$ & Mean & $\mathrm{SD}$ & Mean & $\overline{\mathrm{SD}}$ & Mean & $\mathrm{SD}$ & Mean & $\mathrm{SD}$ & Mean & SD \\
\hline 1 & 287 & 237 & 3.43 & 1.54 & 122 & 161 & 1.52 & 0.88 & 115 & 91 & 0.82 & 0.55 \\
\hline 2 & 350 & 344 & 4.54 & 2.44 & 165 & 234 & 2.14 & 0.99 & 74 & 30 & 0.49 & 0.26 \\
\hline 3 & 369 & 190 & 4.61 & 1.28 & 224 & 262 & 2.84 & 1.19 & 82 & 43 & 0.46 & 0.33 \\
\hline 4 & 520 & 264 & 4.75 & 1.16 & 295 & 303 & 2.51 & 1.62 & 70 & 66 & 0.41 & 0.44 \\
\hline 5 & 412 & 209 & 4.65 & 1.24 & 222 & 226 & 2.67 & 1.34 & 53 & 56 & 0.35 & 0.36 \\
\hline 6 & 498 & 210 & 4.90 & 1.43 & 247 & 246 & 2.85 & 1.65 & 60 & 67 & 0.31 & 0.38 \\
\hline 7 & 403 & 230 & 4.86 & 1.80 & 205 & 220 & 2.91 & 1.56 & 96 & 79 & 0.57 & 0.47 \\
\hline 8 & 299 & 189 & 4.82 & 2.26 & 144 & 155 & 2.75 & 1.12 & 81 & 22 & 0.78 & 0.35 \\
\hline 9 & 340 & 284 & 4.30 & 1.63 & 150 & 267 & 2.01 & 1.04 & 70 & 50 & 0.74 & 0.46 \\
\hline 10 & 250 & 189 & 4.20 & 1.56 & 105 & 106 & 2.41 & 0.93 & 93 & 23 & 1.08 & 0.55 \\
\hline
\end{tabular}

The mean outputs for our patients are given in the table. The high standard deviation reflects the variation between patients, ranging from 100 to $1119.5 \mathrm{mmol} \mathrm{Na}$, and 1.2-10.5 litres of fluid loss per day. The cause of these large losses, and the reason for variation between patients is not clear. It is possible that this phenomenon is mediated by factors released by the intestinal graft. It is essential to monitor and respond to these large losses in a timely fashion to avoid circulatory and renal decompensation. 